\title{
Feeding Experiences of Paulownia Spp. Leaves: Potential Forage Source for Domestic Animals
}

\section{Akos Bodnar ${ }^{1 *}$, JozsefSteier ${ }^{2}$, Rubina T Szabo ${ }^{1}$, Peter Poti ${ }^{1}$, Istvan Egerszegi ${ }^{1}$ and Ferenc Pajor ${ }^{1}$}

${ }^{1}$ Szent Istvan University, Faculty of Agricultural and Environmental Sciences, Institute of Animal Husbrandry, 2100 Godollo, Pater Karoly. 1, Hungary

${ }^{2}$ SUNWO Ltd., 1062 Budapest, Andrassy 56, Hungary

\section{Mini Review}

Volume 3 Issue 1

Received Date: February 20, 2020

Published Date: February 27, 2020

DOI: $10.23880 /$ izab-16000212

*Corresponding author: Akos Bodnar, Faculty of Agricultural and Environmental Sciences, Institute of Animal Husbrandry, Szent Istvan University, 2100 Godollo, Pater Karoly 1, Hungary, Tel: +36-303988364; Email: bodnar.akos@mkk.szie.hu

\section{Abstract}

Paulownia spp. is a very adaptable, fast growing and multi-purpose agroforestry tree. This species is a genus of Asian hardwood trees which have been cultivated there for the past 3000 years. They are native to much of China, south to northern Laos and Vietnam, and long cultivated elsewhere in eastern Asia, notably in Japan and Korea. Paulownia plays a very critical role in providing timber, fuel wood, fodder and food in many countries of the World. Besides its fast-growing nature and several utilization opportunities, Paulownia leaves have similar feeding value to other forage crops. Due to previous studies, it has been reported that Paulownia leaves are suitable for feeding to domestic animals.

Keywords: Paulownia sp; Composition; Forage; Protein Source

\section{Introduction}

Interest in Paulownia is gaining momentum around the world, due to its fast-growing nature, the ability to take up nutrients and the potential for intercropping $[1,2]$. Several research projects have been done in the last decades due to the adaptation, utilization, production etc. of Paulownia species and hybrids around the World [3-5]. According to these researches, one can conclude that Paulownia species and hybrids can produce and show extremely good results in growth rates, biomass production and $\mathrm{CO}_{2}$ (and dust) absorption, as well [6,7].

With optimal conditions in terms of light and moisture, Paulownia is reported to be one of the fastest growing trees in the world [8]. It is mainly suggested to use hybrids of Paulownia species as the basic trees for forestation and intercropping systems $[9,10]$. Several kinds of hybrids have been selected during the last few decades around the
World, according to the environmental conditions and local circumstances (e.g. temperature, salinity, water supply etc.).

Paulownia tomentosa is a great bee forage plant because it can produce pollen and nectar too. The flower blooming is in the spring (from April to May) and $700 \mathrm{~kg}$ honey is expected from 1 hectar Paulownia tomentosa field [11]. Besides that, flowers of Paulownia fortunei can attract plenty of insect species (Apis mellifera, A. dorsata, Megachile bicolour, carpenter and solitary bees) and assure nectar and pollen that other Paulownia varieties [12].

Paulownia leaves are reported to have a similar feeding value to alfalfa and are suitable for combining with wheat straw or hay for feeding to cattle, sheep or goats $[10,13]$. World Paulownia Institute [13] stated that if trees are planted at 540 trees/ha, Paulownia will produce 1220 $\mathrm{kg}$ DM/ha with $20 \%$ protein and $60 \%$ digestibility. A Paulownia tree that is 8-10 years old is reported to have 100 
$\mathrm{kg}$ fresh leaves, with 2.8-3 \% Nitrogen $(\mathrm{N})$ and $0.4 \%$ potash. Chemical composition of the Paulownia leaf is also detailed as $7.8 \%$ ash, $22.6 \%$ protein, $91.4 \%$ organic matter, $0.6 \%$ phosphorus, $2.1 \%$ calcium, $0.6 \%$ iron, $0.9 \%$ zinc, with $15-18$ $\mathrm{MJ} / \mathrm{kg}$ metabolizable energy [14]. The potential of the leaves as an ensiled fodder crop for Northern Ireland may warrant investigation, perhaps in mini-silos. When the leaves fall, they can be a valuable source of organic matter and nutrients for the soil and can also be used for compost $[1,15]$.

Use of Paulownia leaves as potential feed for domestic animals is a relatively new approach and research field. The genus of Paulownia is potential forage in the goat nutrition system. Six genotypes of Paulownia (P. fortunei, P. tomentosa, $P$. elongata and three clones of $P$. elongata) were compared to investigate the growth of the seedlings and browse preference of Boer does. The clones had more brances and were taller than seedling. In the seedling group, $P$. fortunei produced higher degree of brancing $(87.0 \mathrm{~cm})$ and taller herbage (2.2) in the second year. There were no significant differences are mortality (average $4.8 \%$ ). Preference trends were not noticed during the two separate grazing sessions among the six Paulownia genotypes [16]. Dried Paulownia elongata as a feed supplement was added to yearling sheep feed to investigate changes of some blood parameter. The counts of leukocyte and erythrocyte were significantly reduced 2.5 hour after intake. During the feeding trial, blood glucose value significantly decreased, probably because of the changes in proportion of fatty acids. The experimental diet increased the total serum protein amount [17]. Stewart, et al. [18] provided evidence to the suitability of growing P. elongata trees as a multipurpose crop in middle Georgia, U.S. They collected fresh leaf samples from 30 months old P. elongata trees, for drying and making $75 \%$ and $95 \%$ Paulownia pellets. In this study, the estimated digestible dry matter (DDM) for Paulownia based feed pellets is $65.20 \%$.

Al-Sagheer, et al. [19] examined the nutrition effects of two Paulownia tomentosa leaf meal (PLM) (15\% and $30 \%$ in the feed) in 5-week-old New Zealand White rabbit males. In the case of nutrient digestibility, no significant differences were found. Total protein values increased in rabbits, too. The high-density lipoprotein (HDL) concentration significantly increased, while the low-density lipoprotein (LDL) value decreased in each experimental group. PLM diet had no negative affect on the blood biochemistry parameters and did not influence the carcass traits. Feed intake $(90.27$ $\mathrm{g})$ and feed conversion ratio $(3.63 \mathrm{~g} / \mathrm{g})$ were lower in the 15 $\%$ PLM diet compare to $30 \%$ PLM and control groups. The antimicrobial properties of Paulownia tomentosa appeared, because the total bacterial and fungi counts were reduced in the basal PLM feed, same trend was found in the cecum. Results of Wang, et al. [20] showed that polysaccharides from Paulownia fortunei flowers (PFFPS) can amend the immune system because of the improvement of the cellular and the humoral immunity in chicken. All PFFPS groups (40, 20 , and $10 \mathrm{mg} / \mathrm{mL}$ ) represented higher leukocyte counts and lymphocyte ratios than cyclophosphamide or phosphatebuffered saline groups. Values of bodyweight, thymus, bursa of Fabricius and spleen weight were the most favourable among all of the groups, therefore it is stated that PFFPS can increase the growth rate and improve the immune status of healthy and immunosuppressed chickens [20]. Other in vivo chicken investigation demonstrated that polysaccharides from Paulownia tomentosa (PTFP) can enhance the cellular immune mechanisms against Newcastle disease. The highest lymphocyte proliferation rate and adjuvant activity are appeared at the concentration of $12.5 \mathrm{mg} / \mathrm{kg}$ PTFP. Humoral immunity was triggered in PTFP groups too, especially with PTFP at concentration $25 \mathrm{mg} / \mathrm{kg}$. Therefore 12.5 or $25 \mathrm{mg} /$ kg PTFP is the appropriate dose to significantly increase the response of the immune system [21]. Additionally Popova, et al. [22] determined the antimicrobial activity of freash Paulownia elongata leaf and silage from these leaves in vitro. It was found that the minimum inhibitory concentrations (MICs) of the aqueous extract of fresh leaves was $80.6 \pm 19.5 \mu \mathrm{g} / \mathrm{mL}$. The MICs value of the silage was lower $(58.3 \pm 13.9 \mu \mathrm{g} / \mathrm{mL})$, therefore the antimicrobial effect of that is higher, probably because of the lower value of $\mathrm{pH}$. Paulownia elongata leaves and silage showed antimicrobial activity against common pathogens (Salmonella enterica, Pseudomonas aeruginosa, Streptococcus pyogenes, Candida albicans) in vitro, so the application of Paulownia elongata as a livestock forage would be beneficial to the animal health.

Investigation of the nutritional values of fresh Paulownia spp. hybrid leaves (P. elongata, P. fortunei and P. tomantosa) it was found that the dry matter of Paulownia leaves is relatively low (286.4 g/kg dry matter, DM) [10]. It is lower than the values reported for tree leaves (46-66 \% of kg DM) by Azim. The crude protein content was medium high (117.5 $\mathrm{g} / \mathrm{kg} \mathrm{DM}$ ) for a fresh forage, and similar than that reported for Paulownia spp. (160-200 g/kg DM), by Mueller, et al. [16] and Stewart, et al. [18]. This value compares favourably with other values reported by Addlestone, et al. [23] for leguminous browse species such as Robinia pseudoacacia.

The fatty acid composition was also determined by Bodnar, et al. [10]. The main fatty acids were palmitic acid (C16:0), oleic acid (C18:1n9c), linoleic acid (C18:2n6) and linolenic acid (C18:3n3). In our study, the green plant $\alpha$-linolenic acid concentration in total fat was $24.6 \%$, the $n-6 / n-3$ ratio was less than 1 . The $\alpha$-linolenic acid concentration of green maize reached $30 \%$ [24], grass is also rich in $\alpha$-linolenic acid account for about $40-50 \%$ of the total fat in grass $[25,26]$. In terms of the $n-3$ fatty acids composition was suitable for improving the contents of milk health promoters. 


\section{Conclusion}

The nutritive value of the fresh Paulownia is relatively high $(177.5 \pm 4.9 \mathrm{~g} \mathrm{CP} / \mathrm{kg} \mathrm{DM})$ and it could be considered as good PUFA source as grass for the ruminants. In terms of the crude protein contents, particularly in terms of the fatty acid composition was suitable for use as feeding by sheep, goat or cattle. However, in practical feeding situations, sheep on low crude fibre content forage crops must have access to a source of roughage (straw, hay) adequate for maintenance of proper rumen activity.

Finally, one can conclude that Paulownia leaves could be used as forage of domestic animals in some parts of the World, similar to China, where the leaf of Paulownia spp. is collected in autumn and fed by cattle, sheep and pigs. Nowadays, mostly fresh leaves are fed by the animals, but some results show that the pellet form can be also a good solution.

\section{References}

1. Wang Q Shogren JF (1992) Characteristics of the cropPaulownia system in China. Agriculture, Ecosystem and Environment 39(3-4): 145-152.

2. Jianbo L (2006) Energy balance and economic benefits of two agroforestry systems in northern and southern China. Agriculture, Ecosystem and Environment 116(34): 255-262.

3. Ates SY, Ni MA, Tozluoglu A (2008) Characterization and evaluation of Paulownia elongata as a raw material for paper production. African Journal of Biotechnolgy 7(22): 4153-4158.

4. Kalaycioglu H, Deniz I, Hiziroglu S (2005) Some of the properties of particleboard made from Paulownia. Journal of Wood Science 51: 410-414.

5. Rafighi A, Tabarsa $T$ (2011) Manufacturing high performance wood composite panel from paulownia. Key Engineering Materials 471-472: 1091-1094.

6. Ayrilmis N, Kaymakci A (2013) Fast growing biomass as reinforcing filler in thermoplastic composites: Paulownia elongata wood. Industrial Crops and Products 43: 457464.

7. Woods VB (2008) Paulownia as a novel biomass crop for Northern Ireland? A review of current knowledge. AgriFood and Biosciences Institute, Global Research Unit No.7, Hillsborough.

8. Burns RM, Honkala BH (1990) Silvics of North America. U.S. Department of Agriculture, Forest Service,
Agriculture Handbook 654, , Washington DC, USA.

9. Guo XY (1990) Final technical report of Paulownia project. International Development Research Centra (IDRC), Canada and the Chinese Academy of Forestry, Beijing, China.

10. Bodnar A, Pajor F, Steier J, Kispal T, Poti P (2014) Nutritive value of Paulownia (Paulownia spp.) hybrid tree leaves. Hungarian Agricultural Research 23(4): 27-32.

11. Hill DB, Webster TC (1995) Apiculture and forestry (bees and trees). Agroforestry Systems 29: 313-320.

12. Shankar U, Abrol DP (2015) Plants for Bees: Paulownia fortune. Bee World 92(3): 90-91.

13. (2020) World Paulownia Institute.

14. El-Showk S, El-Showk N (2003) The Paulownia Tree: An Alternative for Sustainable Forestry.

15. Lyons A (1993) Paulownia. Agroforestry-Trees for Productive Farming. In: Race D, Agmedia, Melbourne E, et al. (Eds.).

16. Mueller JP, Luginbuhl JM, Bergmann BA (2001) Establishment and early growth characteristics of six Paulownia genotypes for goat browse in Raleigh. Agroforestry Systems 52: 63-72.

17. Vaslyakov I, Radev V, Stavov T, Ganchev G (2013) Blood parameters in yearling sheep fed Paulownia (Paulownia spp.) leaves. Agricultural Science and Technology 5(4): 405-409.

18. Stewart WM, Vaidya BN, Mahapatra AK, Terrill TH, Joshee N (2018) Potential Use of Multipurpose Paulownia elongata Tree as an Animal Feed Resource. American Journal of Plant Sciences 9(6): 1212-1227.

19. Al-Sagheer AA, El-Hack AEA, Alagawany M, Naiel MA, Mahgoub SA, et al. (2019) Paulownia leaves as a new feed resource: chemical composition and effects on growth, carcasses, digestibility, blood biochemistry, and intestinal bacterial populations of growing rabbits. Animals 9(3): 95.

20. Wang Q, Meng X, Zhu L, Xu Y, Cui W, et al. (2019) Polysaccharide found in Paulownia fortunei flowers can enhance cellular and humoral immunity in chickens. International Journal of Biological Macromolecules 130: 213-219.

21. Yang H, Zhang P, Xu X, Chen X, Liu Q, et al. (2019) The enhanced immunological activity of Paulownia tomentosa flower polysaccharide on Newcastle disease 
vaccine in chicken. Bioscience Reports 39(5): 1-9.

22. Popova TP, Baykov BD (2013) Antimicrobial activity of aqueous extracts of leaves and silage from Paulownia elongate. American Journal of Biological, Chemical and Pharmaceutical Sciences 1(2): 8-15.

23. Addlestone BJ, Mueller JP, Luginbuhl JM (1998) The establishment and early growth of three leguminous tree species for use in silvopastoral systems of the southeastern USA. Agroforestry Systems 44: 253-265.

24. Pajor F, Gallo O, Poti P (2013) Milk and cheese fatty acid profiles in Alpine goat fed green maize forage. Journal of Animal and Feed Sciences 22: 213-218.

25. Cabiddu A, Decandia M, Addis M, Piredda G, Pirisi A, et al. (2005) Managing Mediterranian pastures in order to enhance the level of beneficial fatty acids in sheep milk. Small Ruminant Research 59(2-3): 169-180.

26. Pajor F, Gallo O, Steiber O, Tasi J, Poti P (2009) The effect of grazing on the composition of conjugated linoleic acid isomers and other fatty acids of milk and cheese in goats. Journal of Animal and Feed Sciences 18: 429-439. 